\title{
Comparative Assessment of Newly Designed Burial Type Lowland Power Cultivator for Weed Control
}

\author{
G.V.T.V. Weerasooriya*, D.N. Jayatissa ${ }^{1}$ and M. Rambanda ${ }^{2}$ \\ Postgraduate Institute of Agriculture \\ University of Peradeniya \\ Sri Lanka
}

\begin{abstract}
Weeds are the major reason for the significant yield reduction in rice cultivation worldwide. Power weeders have been introduced to rice cultivation as an alternative solution for the controversial herbicide applications. The aim of this study was to appraise the newly designed burial type lowland power cultivator through a comparative performance assessment including cost economics. Five weeding methods using Conoweeder $\left(T_{1}\right)$, Modified "Asakura" wooden clog $\left(T_{2}\right)$, Rotary power weeder $\left(T_{3}\right)$, Newly designed lowland power cultivator $\left(T_{4}\right)$ and manual weeding $\left(T_{5}\right.$ as the control) were evaluated. The $T_{4}$ showed a significantly high field capacity of $0.04 \mathrm{ha} / \mathrm{h}$, which is 8 times higher than $T_{5}$, high field efficiency of $88.30 \%$ and weeding efficiency of $62.29 \%$ which was similar to the performance of $T_{5}$. Significantly high performance indexes were observed in $T_{2}$ and $T_{4}(461.65)$ followed by $T_{1}$ and $T_{3}$. Plant damage percentage, maximum tiller number and the yield did not show any significant variation $(p>0.05)$ among weed control methods assessed. Further, the $T_{4}$ showed a significantly low cost of weeding of 6583 Rs/ha which was $76 \%$ of cost reduction of the $T_{5}$, and moderately high break-even point of 0.88 ha/yr suggesting that it is appropriate for the medium and large scale farmers. Moreover, $T_{4}$ showed low fuel consumption $(0.556 \mathrm{~L} / \mathrm{h})$ and power requirement $(0.57 \mathrm{~kW})$ representing $48 \%$ and $42 \%$ respective reductions over the $T_{3}$. Further, $T_{4}$ showed the significant lowest weed re-growth rate which is essential for sustainable weed control. Based on the above results, newly designed burial type power cultivator could be recommended for medium and large scale paddy farming, since it showed high performance compared to other methods assessed. Machine performance could be further improved by high speed, light weight design with efficient turning mechanism. Besides, it is suggested to conduct detailed ergonomic evaluation in future investigations.
\end{abstract}

Keyword: Burial type cultivator, manual weeding, mechanical weeding, paddy cultivation

\section{INTRODUCTION}

Weed is one of the most important agricultural problems and its competitive nature causes serious negative effects in crop production and considerable marketed losses in crop yield (Mamun et al., 1993) from 15 to $50 \%$ (Hasanuzzaman et al., 2009). Similarly, weeding is a labour intensive agricultural unit operation and it accounts for about $25 \%$ of total labour requirement (Yadav and Pund, 2007a).

\footnotetext{
1 Department of Agricultural Engineering, Faculty of Agriculture, University of Peradeniya, Sri Lanka.

${ }^{2}$ University Sub Campus, Mahailluppallama, Sri Lanka.

* Corresponding Author: gvtvw@agri.rjt.ac.lk
} 
The apparent yield loss is due to unrestricted weed competition which makes it laborious in managing weeds. Consequently, introduction of appropriate weeding machineries has become an imperative prerequisite to enhance the rice production.

Chemical methods of weed control had gained recognition among medium and large scale paddy farmers in Sri Lanka, over other existing methods which are laborious and time consuming, leading to higher cost of production and therefore, confined to small scale farming. Nevertheless, excessive utilization of these agro-chemicals leads to negative impact on the environment and human health. As a result, a new trend of minimizing the agrochemical usage has been encouraged among farmers and agricultural policy makers. Correspondingly, some hazardous herbicides were banned recently in Sri Lanka to lessen the potential health impact. However, there should be an appropriate alternative approach to control weeds in rice farming with minimum environmental effects. Because of these reasons as well as concerns over the environmental degradation and growing demand for organically produced food, mechanical method of weed control is imperative (Gobor and Lambers, 2007). Therefore, the Department of Agriculture (DOA) in Sri Lanka is promoting the usage of mechanical power weeders for medium and large scale paddy farmers as an alternative approach to chemical weed control. Similarly, it has been considered as a solution of weed control for mechanically transplanted paddy fields by introducing mechanical power transplanters. As a result of that, several power weeders have been imported and distributed among paddy farmers. Most of them consist of rotary action and they have not been much popular among Sri Lankan farmers.

Recently, Rajarata University of Sri Lanka designed a new burial type lowland power cultivator which could be considered as an appropriate solution for the weeding problem faced by medium and large scale paddy farmers in Sri Lanka. The most significant feature of this design is the weed burying unit, which may cause to increase the organic matter content of the soil while loosening the soils (Jayatissa and Wickramasinghe, 2010). However, this machine cannot be recommended for farmers since this machine has not been undergone a comparative performance evaluation.

Therefore, the present study was conducted to assess the newly designed burial type lowland power cultivator through a comparative performance assessment. The output of this research would provide comparative field performances and economics of currently used lowland weeders in Sri Lanka. These findings could be used to make recommendations and required modifications to the new design. Hence this outcome would be beneficial for farmers, researchers, farm machinery producers and policy makers in different agricultural sectors.

\section{MATERIALS AND METHODS}

Four types of equipment namely cono-weeder, modified "Asakura" wooden clog, rotary power weeder and newly designed lowland power cultivator were used for this evaluation. Cono-weeder and modified "Asakura" wooden clog are manual weeders and can easily be operated by one man. Other two, rotary power weeder and newly designed lowland power cultivator are powered by $1.46 \mathrm{~kW}$ and $1.57 \mathrm{~kW}$, small petrol engines, respectively. The cono-weeder (push-pull type, manually operated weeder) has a weeding unit width of $20 \mathrm{~cm}$ and partially one row is covered during its single pass. The two cones and serrated blades are made up of Mild Steel (MS) sheets. The second equipment is a pair of "Asakura" wooden clogs having a weeding unit width of $20 \mathrm{~cm}$ x 2 and partially two rows of paddy can be covered at a time during a single pass of this equipment. The frame and foot are made up of 
light wood and piano wire, respectively. The third equipment is a rotary power weeder having a working width of $36 \mathrm{~cm}$ and two rows of paddy can be covered at a time during a single pass. The weeding spike of the rotor is made up of MS sheet and the rotor of the weeder is made up of an aluminum sheet. Fourth equipment is the newly designed burial type lowland power cultivator having a $90 \mathrm{~cm}$ working width and three rows of paddy can be covered at a time in a single pass. Three weeding clogs were made form MS flat iron and rods. Beside, manual method of weeding, a very common practice, was used as the control for this experiment. Figure 1 shows different equipment used in weeding operation.

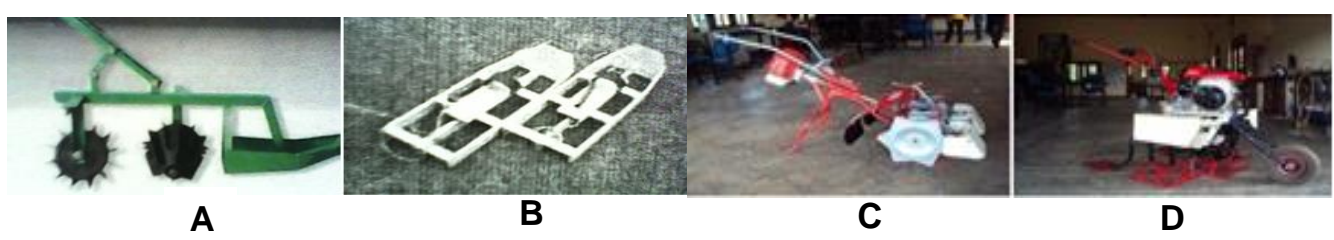

Figure 1. Equipment Used in Weeding Operation.

A: Cono-weeder, B: Modified "Asakura" wooden clog, C: Rotary power weeder and D: Newly designed burial type lowland power cultivator

The study was conducted during 2015/16 "Maha" season in the Research farm of Faculty of Agriculture, Rajarata University of Sri Lanka (RUSL), Puliyankulama, Anuradhapura. This area is located in latitudes; $8^{\circ} 16^{\prime}-8^{\circ} 22^{\prime} \mathrm{N}$ and longitudes; $80^{\circ} 20^{\prime}-80^{\circ} 30^{\prime} \mathrm{E}$ which belongs to $\mathrm{DL}_{1 \mathrm{~b}}$ agro ecological region. Major soils found in this area are Reddish Brown Earths (Rhodustalfs) and Low Humic Gley (Tropaqualfs) (Mapa et al., 2009).

The experiment was conducted as Randomized Complete Block Design (RCBD) with five treatments which included different weed control practices and four replications of each treatment. Five treatments namely; $\mathrm{T}_{1}$ - Cono-weeder, $\mathrm{T}_{2}$ - Modified "Asakura" wooden clog, $\mathrm{T}_{3}$ - Rotary power weeder, $\mathrm{T}_{4}$ - Newly designed lowland power cultivator and $\mathrm{T}_{5}$ - Manual weeding (Control) were used for the comparison of their performances on a uniform basis. RNAM (1983) test codes and procedures for weeders were followed for the evaluation.

The paddy field was prepared by using conventional tillage practices, which included the first ploughing (once), followed by puddling and harrowing (twice) under the flooding conditions by using a power tiller. The main field was divided into 20 subplots with a size of $18.5 \times 2 \mathrm{~m}$ each, by placing drainage channels. BG 352 (Samba) was used as the test variety. Manual transplanting (two plants/hole) was done in $30 \times 14 \mathrm{~cm}$ spacing. Missing hills were filled one week after transplanting (WAT).

Performances of weeders vary with the conditions of the field, soil, weed, crop, power source, operator and the ambient conditions. As the field and soil parameters, the location, area of the field, soil moisture content (MC) and depth of standing water, bulk density (BD) and cone index $(\mathrm{CI})$ were considered. Soil MC was determined by gravimetric method (Majumdar and singh, 2002). The core sampler $(\varnothing=50 \mathrm{~mm})$ was used to collect undisturbed soil samples to determine the BD of the soil (Singh, 1980). ASAE standard S313.2 (ASAE, 1994) was followed to measure CI using Eijkelkamp hand penetrometer. As the weed-related parameters, type of weed, population and height of the weeds were considered. Population and height of the rice plants were measured as crop parameters. All the field tests and 
evaluations were conducted on uniformly inundated paddy fields, using skilled operators, avoiding extreme weather conditions to maintain the test uniformity.

Performance indicators such as effective field capacity, field efficiency, weeding efficiency and plant damage percentage were calculated as described in RNAM (1983). The performance index was calculated by using Equation 01 as described by Srinivas et al., (2010). Maximum tiller number was counted at 5 WAT. Net plot yield was determined at the end of the season.

where,

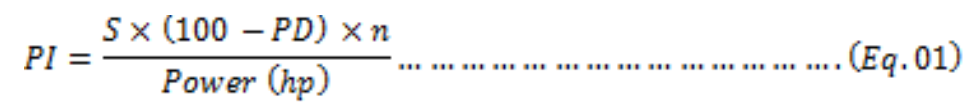

$$
\begin{array}{llll}
\mathrm{PI} & =\text { Performance Index } & \mathrm{S} & =\text { Field capacity }(\mathrm{ha} / \mathrm{h}) \\
\mathrm{PD} & =\text { Plant damage }(\%) & \mathrm{n} & =\text { Weeding efficiency }(\%)
\end{array}
$$

In order to assess and compare weeding costs in each of the above treatments, all cost of wages in manual methods and the fixed \& variable costs in mechanical methods were calculated. Further, fuel consumption and labour requirement were also considered. The fixed cost includes depreciation cost, interest, insurance, tax, housing, repair \& maintenance cost and it is a function of purchase value, useful life and interest rate. Insurance and taxes has been assumed to be negligible for the equipment. The machine salvage value was considered to be $10 \%$ of purchase value (Singh et al., 1988). Mean annual depreciation cost and Interest were determined from straight-line method as described by (Kepner et al., 1982). The cost for housing, repair and maintenance were $10 \%, 1.5 \%$ and $8 \%$, respectively, of purchase value and were calculated as described in RNAM 1983 (Alizadeh et al., 2007). Then hourly fixed cost was calculated as per the Equation 02 by considering annual operation of the equipment as 300 hours (RNAM, 1983).

$$
\text { Hourly Fixed Cost }=\frac{\text { Annual Fixed Cost }}{\text { Operating Hours per year }} \ldots \ldots \ldots \ldots \ldots(E q .02)
$$

Variable costs include fuel \& lubricant and operator cost and these costs are directly related to the amount of work done by the machine. Fuel charge has been determined based on actual fuel consumption and its prevailing rate in the market (Rs. 117.00 per liter of petrol). Labour charge has been considered as per the prevailing rate (Rs. 1000.00) per day ( $8 \mathrm{~h}$ work). Lubrication charge has been assumed as $10 \%$ of the fuel charge. The cost of operation was calculated by adding hourly fixed cost and variable costs as described by Hunt (1995). Finally, the hourly total cost was converted into the weeding cost of unit area (hectare) by dividing the field capacity as described in RNAM (1983).

The break-even point is the area that a machine has to work per year in order to justify owning the machinery was determined by Equation 03. In addition, depth of cut, traveling speed, weed re-growth efficiency and power consumption were also studied.

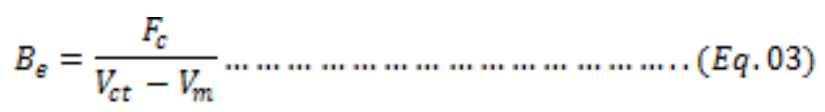

where,

$\mathrm{B}_{\mathrm{e}}=$ Break-even point (ha/yr) $\quad \mathrm{V}_{\mathrm{ct}}=$ Variable costs for manual method (Rs./ha)

$\mathrm{F}_{\mathrm{c}}=$ Fixed costs (Rs./yr) $\quad \mathrm{V}_{\mathrm{m}}=$ Variable costs for machinery method (Rs./ha) 


\begin{abstract}
Data analysis
Collected data were represented by using descriptive statistics. Variables were pre-checked for outliers using Box-plot / Grubbs test, normality and homoscedasticity / homogeneity of variance by using residual plots. Statistical tests, Anderson-Darling and Bartlett's test $(\mathrm{P} \leq 0.05)$ of Minitab 17 software were used to test the normality and homoscedasticity/homogeneity of variance, respectively. The variables that violate normality and homoscedasticity were transformed by using optimal normalizing transformation described by Box and Cox (1964). The significance of the treatments was tested by using analysis of variance (ANOVA) procedure using SAS software at $0.05(\alpha)$ level. Duncan's multiple range test (DMRT) was used to separate the means of significant variables. Further, the variables which failed to find suitable transformation were analyzed using Friedman test, and median were separated by Mann-Whitney test using Minitab 17 software.
\end{abstract}

\title{
RESULTS AND DISCUSSION
}

The evaluation was performed on a paddy field which had $3.7 \mathrm{~cm}$ of average stagnated water. There were no significant differences of test conditions among treatments or blocks $(p=0.05)$. Experimental field showed average field and soil conditions such as soil moisture content of $38.4 \%$ on dry basis, bulk density of $1.54 \mathrm{~g} / \mathrm{cm}^{3}$, cone index of $105.98 \mathrm{kN} / \mathrm{m}^{2}$ and average weed and plant conditions such as a density of 821 weeds $/ \mathrm{m}^{2}$, height of the weed $32.9 \mathrm{~cm}$, population of 146 plants $/ \mathrm{m}^{2}$ and height of the plant $37.6 \mathrm{~cm}$. Further, major weed categories present in the experimental field were $62.4 \%$ of sedges, $25.1 \%$ of grasses and $12.5 \%$ of broad leaves.

Results of the ANOVA and mean comparison for field performances in comparative performance evaluation are summarized in Table 1. While field capacity, field efficiency, weeding efficiency, performance index, cost of weeding and break-even point varied significantly among treatments $(p<0.05)$, plant damage $\%$, maximum number of tillers and yield were not significantly different among the treatments $(P>0.05)$.

Significantly higher average effective field capacities (FC) were recorded in power weeders; $\mathrm{T}_{3}$ - Rotary power weeder $(0.045 \mathrm{ha} / \mathrm{h})$ and $\mathrm{T}_{4}$ - Newly designed lowland power cultivator $(0.040 \mathrm{ha} / \mathrm{h})$, followed by modified "Asakura" wooden clog $\left(\mathrm{T}_{2}\right)$ and Cono-weeder $\left(\mathrm{T}_{1}\right)$ which worked up to 59, 43, 17.5 and $35 \mathrm{~mm}$ depths, respectively (Table 1). The significantly lowest average FC $(0.005 \mathrm{ha} / \mathrm{h})$ was observed in manual weed control $\left(\mathrm{T}_{5}\right)$ with zero depth of cut; it is due to the lower power output of manual labour. However, there was no significant difference between $\mathrm{T}_{3}$ and $\mathrm{T}_{4}$. Further, $\mathrm{FC}$ of $\mathrm{T}_{4}$ and $\mathrm{T}_{3}$ were $800 \%$ and $900 \%$, respectively which were higher than control $-\mathrm{T}_{5}$. In general, due to their faster movement and their higher cutting width, the power weeders can cover large field so that they may have higher FC compared to others. As described by Kumar et al., (2014), the difference in field capacity of different tool/implement is due the width of soil cutting part and forward speed. In $\mathrm{T}_{4}$, the working width $90 \mathrm{~cm}$ is fixed and average travelling speed $9.32 \mathrm{~m} / \mathrm{min}$ was lower. Hence, FC of $\mathrm{T}_{4}$ could further be increased by using higher forward speed through higher gear ratios. However, it would badly affect the weeding efficiency and damaged plant percentage in agreement with the results of Alizadeh, (2011); Remesan et al., (2007); Yadav and Pund, (2007b). However, contradictory results were reported by Maithripala et al., (2013), Rathnasekara et al., (2013), Subudhi (2004) and Parida (2002) in several comparative performance evaluations. Furthermore, Tajuddin (2009) in India and Wijekoon et al., (2008) in Sri Lanka have developed power weeders and reported partially supportive results. 
Table 1. Comparative performances of different weeding methods

\begin{tabular}{|c|c|c|c|c|c|c|c|c|c|}
\hline \multirow[t]{2}{*}{ Sourc } & \multicolumn{9}{|c|}{ Field performances } \\
\hline & Fc & $\mathbf{F e}$ & We & Pd & PI & Tn & Yd & $\mathrm{Cw}$ & Bp \\
\hline \multirow{3}{*}{$\begin{array}{l}\text { Mo } \\
\text { d } \\
\text { Trt } \\
\text { CV }\end{array}$} & $\begin{array}{c}<0.0001 \\
*\end{array}$ & $\begin{array}{c}<0.0006 \\
*\end{array}$ & $0.0089 *$ & $\begin{array}{c}0.274 \\
0\end{array}$ & $0.0120^{*}$ & 0.2333 & 0.0576 & $\begin{array}{c}<0.0001 \\
*\end{array}$ & $<0.0001 *$ \\
\hline & $\begin{array}{c}<0.0001 \\
*\end{array}$ & $\begin{array}{c}<0.0002 \\
*\end{array}$ & $0.0038^{*}$ & $\begin{array}{c}0.908 \\
9\end{array}$ & $0.0033^{*}$ & 0.0879 & $0.0361 *$ & $\begin{array}{c}<0.0001 \\
*\end{array}$ & $<0.0001 *$ \\
\hline & 11.2 & 6.2 & 15.8 & 138.7 & 24.9 & 15.8 & 16.6 & 23.0 & 3.4 \\
\hline $\mathrm{T}_{1}$ & $0.023^{\mathrm{c}}$ & $66.49^{c}$ & $43.43^{c}$ & $0.77^{\mathrm{a}}$ & $357.7^{\mathrm{bc}}$ & $10.33^{\mathrm{a}}$ & $4572^{\mathrm{a}}$ & $5770^{c}$ & $0.07^{\mathrm{c}}$ \\
\hline $\mathbf{T}_{2}$ & $0.032^{\mathrm{b}}$ & $78.87^{\mathrm{b}}$ & $57.93^{\mathrm{ab}}$ & $0.39^{\mathrm{a}}$ & $580.41^{\mathrm{a}}$ & $10.42^{\mathrm{a}}$ & $3564^{\mathrm{a}}$ & $4025^{d}$ & $0.03^{\mathrm{d}}$ \\
\hline $\mathbf{T}_{3}$ & $0.045^{\mathrm{a}}$ & $86.47^{\mathrm{ab}}$ & $44.58^{\mathrm{bc}}$ & $0.76^{\mathrm{a}}$ & $209.57^{\mathrm{c}}$ & $9.50^{\mathrm{a}}$ & $4053^{\mathrm{a}}$ & $8584^{\mathrm{b}}$ & $1.65^{\mathrm{a}}$ \\
\hline $\mathbf{T}_{4}$ & $0.040^{\mathrm{a}}$ & $88.30^{\mathrm{a}}$ & $62.29^{\mathrm{a}}$ & $0.77^{\mathrm{a}}$ & $416.65^{\mathrm{ab}}$ & $12.25^{\mathrm{a}}$ & $4158^{\mathrm{a}}$ & $6583^{c}$ & $0.88^{\mathrm{b}}$ \\
\hline $\mathbf{T}_{5}$ & $0.005^{\mathrm{d}}$ & $90.09^{\mathrm{a}}$ & $70.56^{\mathrm{a}}$ & $0.39^{\mathrm{a}}$ & $\mathrm{Nc}$ & $8.75^{\mathrm{a}}$ & $5403^{\mathrm{a}}$ & $27840^{\mathrm{a}}$ & $\mathrm{Nc}$ \\
\hline \multicolumn{10}{|c|}{ 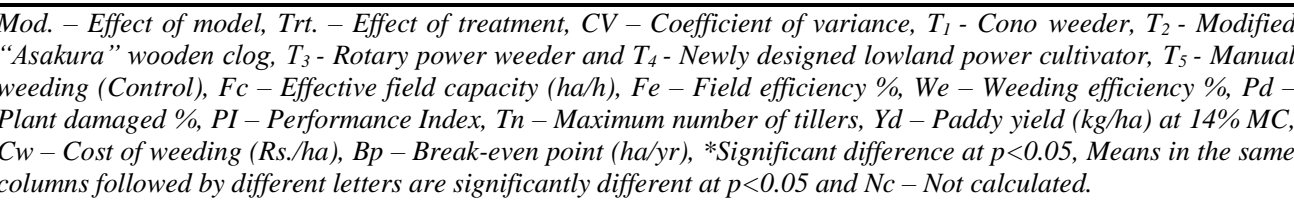 } \\
\hline
\end{tabular}

The highest significant field efficiencies (Fe) were observed in $\mathrm{T}_{5}-$ control $(90.09 \%)$ and newly designed lowland power cultivator; $\mathrm{T}_{4}(88.30 \%)$. In addition, the cono-weeder $\left(\mathrm{T}_{1}\right)$ showed the significantly lowest $\mathrm{Fe}(66.49 \%)$. However, there was no any significant difference between $\mathrm{T}_{2}$ and $\mathrm{T}_{3}$ at $0.05 \alpha$ level. In $\mathrm{T}_{5}$, there was no waste time except operator's rest, and utilizes the full working width (inter row spacing), so that it gave the highest Fe. $\mathrm{T}_{4}$ showed $1.79 \%$ non-significant deviation over the control $\left(\mathrm{T}_{5}\right)$. Moreover, Fe of $\mathrm{T}_{4}$ could be maximized by reducing the time for un-productive work such as turning. Supportive results have been discussed in several studies (Alizadeh (2011); Remesan et al. (2007); Rathnasekara et al. (2013)). Moreover, Maithripala et al. (2013) developed a hand operated mechanical weeder in Sri Lanka which has a Fe of $0.75 \%$.

Manual weed control $\left(\mathrm{T}_{5}\right)$, newly designed power cultivator $\left(\mathrm{T}_{4}\right)$ and modified "Asakura" wooden clog $\left(\mathrm{T}_{2}\right)$ showed significantly higher Weeding efficiency (We) among all treatments. This may be due to more precise intra row area covering in $\mathrm{T}_{5}$ and the efficiency of the weed burring action in $\mathrm{T}_{4}$ and $\mathrm{T}_{2}$, respectively. Furthermore, significantly lowest performances were registered for $\mathrm{T}_{1}(43.43 \%)$, and $\mathrm{T}_{3}(44.58 \%)$. However, there was no significant difference between $\mathrm{T}_{1}$ and $\mathrm{T}_{3}$ at $0.05 \alpha$ level. Furthermore, weeding efficiency for $\mathrm{T}_{4}$ was found to be $8 \%$ lower than the control $\left(\mathrm{T}_{5}\right)$. Generally, weeding efficiency depends on weeder type, weed species, and the weeding time. If weeding is delayed, weeding efficiency will be reduced by excessive growth of the weeds in the soil and improper involvement of machine blades in the soil Alizadeh (2011). Supportive results have been reported by Alizadeh (2011); Remesan et al. (2007); Rathnasekara et al. (2013); Parida, (2002); Subudhi (2004); Yadav and Pund, (2007b) in previously conducted comparative studies. Wijekoon et al. (2008) and Maithripala et al. (2013) developed power and manual weeder, respectively, and they reported that weeding efficiency of them were 92.86 and $88 \%$, respectively. However, the observed values were slightly lower compared to present study because of not practicing manual intra-row weeding during operation.

All treatments showed lower/satisfactory plant damaged percentages (Pd) without having a significant difference among treatments (Table 1). This is mainly due to higher rotating speeds of weeding units, however, when brought nearer to the plant during operation it may 
cause injuries to plants by cutting either their roots or stems. Moreover, greater depth of soil cut and inversion (by rotary weeder) may cause the uprooting of rice plant (Srinivas et al., 2010). Similarly, the highest depth of cut was recorded by $\mathrm{T}_{3}(59 \mathrm{~mm})$ followed by $\mathrm{T}_{4}(43$ $\mathrm{mm})$ and $\mathrm{T}_{1}(35 \mathrm{~mm})$, respectively, which showed a positive relationship with $\mathrm{Pd} \%$. However, $\mathrm{T}_{4}$ showed an increase of $0.38 \%$ of Pd compared to the control $\left(\mathrm{T}_{5}\right)$. Results of a comparative performance evaluation conducted by Alizadeh (2011), Remesan (2007) and Rathnasekara et al. (2013) revealed partially supportive results, but they were higher compared to present readings. Singh and Bhosale (2014) also reported similar relative performances of power weeder and manual weeding in sugarcane cultivation. Besides, Wijekoon et al. (2008) reported zero Pd in testing of lowland power weeder.

Performance index (PI) of weeding equipment is directly related to the field capacity, weeding efficiency and inversely related to exerted power (Srinivas et al., 2010) during the weeding operations. Hence, it would be a good criterion to assess the overall machine performance of mechanical weeders. The modified "Asakura" wooden clog $\left(\mathrm{T}_{2}\right)$ and newly designed lowland power cultivator $\left(\mathrm{T}_{4}\right)$ gave the highest values for PI as 580.41 and 416.65 , respectively, followed by cono-weeder $\left(\mathrm{T}_{1}\right)$. The lowest performance (209.57) was recorded in power rotary weeder $\left(\mathrm{T}_{3}\right)$. However, there was no significant difference between $\mathrm{T}_{1}$ and $\mathrm{T}_{3}$ or $\mathrm{T}_{4}(P>0.05)$. These results attribute the effectiveness of weed burial mechanism over rotary action. $\mathrm{T}_{4}$ gained a higher performance $(120 \%)$ over power rotary weeder $\left(\mathrm{T}_{3}\right)$ which is prominent in the present day market. $\mathrm{T}_{3}$ gained a lower performance $(20 \%)$ over the $\mathrm{T}_{2}$ which is a manual version of it. This may be due to the higher power consumption of $\mathrm{T} 4$ $(0.57 \mathrm{~kW})$ over $\mathrm{T}_{2}(0.32 \mathrm{~kW})$. Results reported by Remesan et al. (2007) and Wijekoon et al. (2008) support the results of the current study.

Though the maximum tiller number (Tn) was not significantly different $(p>0.05)$, newly designed lowland power cultivator $\left(\mathrm{T}_{4}\right)$ and manual weeding control $\left(\mathrm{T}_{5}\right)$ showed the highest (12.25) and lowest (8.75) Tn, respectively. Furthermore, $\mathrm{T}_{4}$ showed the $40 \%$ increase in $\mathrm{Tn}$ compared to control (Table 1). As reported by Jayatissa and Wickramasinghe (2010), Tn should significantly be increased in $\mathrm{T}_{4}$ and $\mathrm{T}_{2}$, due to the weed burying action which may cause higher tillering by increasing the organic matter content while loosening the soil.

However, there was no significant paddy yield (Yd) increase in mechanical weeding $\left(\mathrm{T}_{2}\right)$ compared to manual weeding $\left(\mathrm{T}_{5}\right)$, as reported by Jayatissa and Wickramasinghe (2010). Though it was not significant, the highest and the lowest $\mathrm{Yd}$ were observed in $\mathrm{T}_{5}(5403$ $\mathrm{kg} / \mathrm{ha}$ ) and $\mathrm{T}_{2}(3564 \mathrm{~kg} / \mathrm{ha})$, respectively. Further, there was $23 \%$ yield reduction in $\mathrm{T}_{4}$ compared to control $\left(\mathrm{T}_{5}\right)$.

The highest $\mathrm{Cw}(27,840 \mathrm{Rs} / \mathrm{ha})$ was recorded in control $\left(\mathrm{T}_{5}\right)$ followed by rotary power weeder $\left(\mathrm{T}_{3}\right)$ whereas the lowest $\mathrm{Cw}(4,025 \mathrm{Rs} / \mathrm{ha})$ was achieved by Modified "Asakura" wooden clog $\left(\mathrm{T}_{2}\right)$. Cono-weeder $\left(\mathrm{T}_{1}\right)$ and newly designed lowland power cultivator $\left(\mathrm{T}_{4}\right)$ showed equal performances and they were registered as the second lowest $\mathrm{Cw}$. Similarly, $\mathrm{T}_{4}$ showed a $76 \%$ of cost reduction compared to the conventional weed control method $\left(\mathrm{T}_{5}\right)$. Laborious practices (223 man-h/ha) and minimum field capacity $(0.005 \mathrm{ha} / \mathrm{h})$ in manual weeding may be the reasons for the highest $\mathrm{Cw}$. In addition, the cost of operation of power weeders $\left(T_{3}\right.$ and $\left.T_{4}\right)$ were more than that of manual weeders $\left(T_{1}\right.$ and $\left.T_{2}\right)$ which might be due to higher purchasing price of these implements (Rs. 130,000.00 for $\mathrm{T}_{3}$ and Rs. 72,500.00 for $\mathrm{T}_{4}$ ). This leads to increased fixed costs of operations in spite of higher FC of these machines. Further, $\mathrm{T}_{4}$ showed a lower fuel consumption $(0.556 \mathrm{~L} / \mathrm{h})$ compared to the $\mathrm{T}_{3}(1.069 \mathrm{~L} / \mathrm{h})$. The cost of operation by newly designed power cultivator (T4) and rotary power weeder (T3) were only $1 / 4$ and $1 / 3$ of the cost of manual weeding control, respectively. Similar results 
were also reported by other researches indicating that significant decrease in the mechanized method over hand weeding (Parida, 2002; Tajuddin, 2006; Remesan et al., 2007; Tajuddin, 2009; Singh and Bhosale, 2014). In terms of $\mathrm{Cw}$, the newly designed lowland power cultivator $\left(\mathrm{T}_{4}\right)$ was second only to Modified "Asakura" wooden clog $\left(\mathrm{T}_{2}\right)$ which is the manual version of this power cultivator. Therefore, it can be concluded that newly designed lowland power cultivator has satisfactory performance in $\mathrm{Cw}$.

The highest break-even point $(\mathrm{Bp})$ was recorded in power rotary weeder $\left(\mathrm{T}_{3}\right)$; and it is appropriate for large scale farmers who have annual working extent more than $1.65 \mathrm{ha} / \mathrm{yr}$. This could be attributed to a higher annual fixed cost of this type of power weeders compared to other tested implements. The newly designed lowland power cultivator (T4) showed moderately higher $\mathrm{Bp}$ and it is appropriate for medium and large scale paddy farmers who have annual working extent of more than 0.88 ha/yr. Manually operated weeders such as Cono-weeder $\left(T_{1}\right)$ and modified "Asakura" wooden clog $\left(T_{2}\right)$ showed comparatively low Bps and they were appropriate for small scale paddy farmers who have annual working extents of 0.07 and $0.03 \mathrm{ha} / \mathrm{yr}$, respectively (Table 1).

As illustrated in Figure 2, $\mathrm{T}_{5}$ shows the highest re-growth efficiency; $145 \%$ (at one week after weeding) compared to all other weed control methods. This may be due to partial eradication of weeds by manual uprooting. Further, $\mathrm{T}_{4}$ gave the lowest re-growth efficiency (23\%) which is attributed to the sustainable weed control due to its weed burying mechanism (Jayatissa and Wickramasinghe, 2010). Newly designed lowland power cultivator $\left(\mathrm{T}_{4}\right)$, showed superior performances in weed controlling because it has the highest weeding efficiency (62\%) and the lowest re-growth efficiency (23\%) compared to other evaluated mechanical weeders.

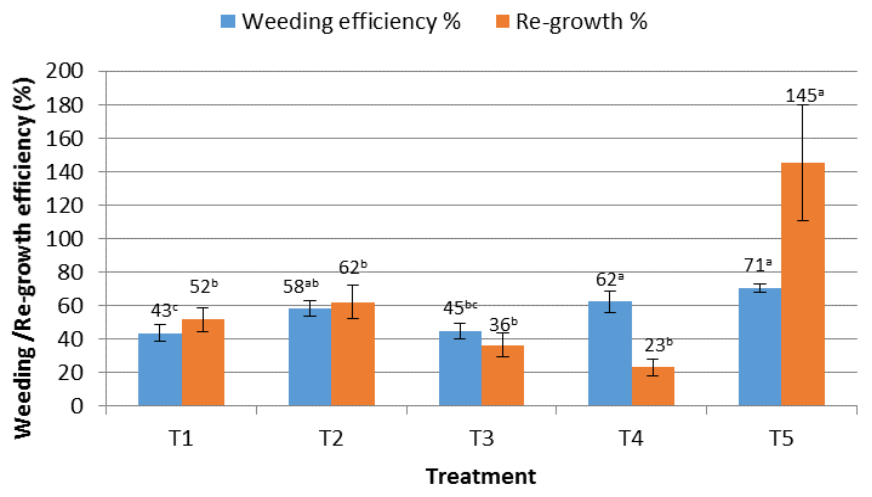

Figure 2. Weeding / Re-growth Efficiencies of Different Treatments

$T_{1}$ - Cono-weeder, $T_{2}$ - Modified "Asakura" wooden clog, $T_{3}$ - Rotary power weeder and $T_{4}$ - Newly designed lowland power cultivator, $T_{5}-$ Manual weeding (Control) and efficiencies with same letters are not significantly different at $\mathbf{p}>\mathbf{0 . 0 5}$.

\section{CONCLUSIONS}

The field performances of different types of weeders that were used for the study showed their own strengths and limitations. However, the newly designed burial type lowland power 
cultivator displayed superior performance in field capacity $(0.040 \mathrm{ha} / \mathrm{h})$, field efficiency $(88.30 \%)$, weeding efficiency (62.29\%), performance index (416.65), higher performances in cost of weeding $(6,583 \mathrm{Rs} . / \mathrm{ha})$ and satisfactory performance in plant damaged percentage $(0.77 \%)$, maximum number of tillers $(12.25)$ and paddy yield $(4,158 \mathrm{~kg} / \mathrm{ha})$, in comparison to other examined weeding methods. The cost of operation and the labour requirement for newly designed lowland power cultivator were $1 / 4^{\text {th }}$ and $1 / 9^{\text {th }}$ to the conventional manual weeding control, respectively. Further, this cultivator showed comparatively lower fuel consumption and power requirement over power rotary weeder and is appropriate for medium and large scale farming. In addition, it shows the significantly lowest weed regrowth rate $(23 \%)$ which leads to sustainable weed controlling. Thus, it can be concluded that newly designed burial type lowland power cultivator could be introduced as an appropriate solution for the weeding problem of medium and large scale paddy farmers in Sri Lanka.

\section{SUGGESTIONS AND RECOMMENDATIONS}

It is suggested to improve the machine performances of newly designed burial type lowland power cultivator; field capacity by using higher travelling speed through higher gear ratios and field efficiency by reducing the time wasted for non-productive work; specially time for the turning by using an improved steering mechanism. Moreover, plant damage percentage could be minimized by adding a guard for the weeding unit / plant guider as in rotary power weeder. To reduce the tediousness of in-farm manipulation and field operation, it is suggested replacing the present front wheel by wider and power-driven wheel and reducing the total weight of the cultivator using light-weight materials. Further, it is suggested to conduct a detailed ergonomic evaluation to confirm the human factor interference.

\section{ACKNOWLEDGEMENT}

Authors would like to thank the Rajarata University of Sri Lanka (RUSL) and University of Peradeniya for providing the opportunity to make this research project a success. Ms. N.N. Senevirathne is acknowledged for her assistance in research activities. This research work was funded by the University Grants Commission (UGC), Sri Lanka.

\section{REFERENCES}

Alizadeh, M.R. (2011). Field performance evaluation of mechanical weeders in the paddy field. Sci. Res. Essays. 6(25), 5427-5434, DOI: 10.5897/SRE11.1412

Alizadeh, M.R., Bagheri, I. and Payman M.H. (2007). Evaluation of a rice reaper used for rapeseed harvesting. American-Eurasian J. Agric. Environ. Sci. 2(4), 388-394.

ASAE. (1994). American Society of Agricultural Engineers. ASAE Standards. 14th Edition, USA.

Box, G.E.P. and Cox, D.R. (1964). An analysis of transformations. J. R .Stat. Soc., B. 26, 211-234. 
Gobor, Z. and Lambers, P. S. (2007). Prototype of a rotary hoe for inter-row weeding. World Congress, Besancon, France: 18-21.

Hasanuzzaman, M.; Ali, M.H., Alam, M.M., Akhtar, M. and Fakhrul, A. K. (2009). Evaluation of pre-emergence herbicide and hand weeding on the weed control efficiency and performance of transplanted rice. American-Eurasian J. Agron. 2(3), 138-143.

Hunt, D. (1995). Farm power and machinery management $\left(9^{\text {th }}\right.$ Edn.). USA: Iowa State University Press. Ames, IA.

Jayatissa D.N. and Wickramasinghe, W.A.M.P. (2010). Final report on Testing Improved Wooden Clog for Weed Control in Row-seeded or Row-planted Paddy Fields. Report submitted to JICA/EAA.

Kepner, R.A., Bainer, R. and Barger, E.L. (1982). Principle of Farm Machinery. $3^{\text {rd }}$ edition. avi, West port, Connecticut.

Kumar, T.N., Kumar, A.S., Nayak, M. and Ramya, V. (2014). Performance evaluation of weeders. Int. J. Environ. Sci. Technol. 3(6), 2160-2165.

Maithripala, S.P.K., Weerasooriya, G.V.T.V., Kahandage, P.D and Ginigaddara, G.A.S. (2013). Design development and testing of combined manual weeder and marker for row planted paddy (SRI method). In Extended Abstracts, 3rd Annual Research Symposium 2013. Rajarata University of Sri Lanka, Sri Lanka, pp 51 - 52.

Majumdar, S.P. and Singh, R.A. (2002). Analysis of soil physical properties. Agrobios (India), Jodhpur.

Mamun, A.A., Karim, S.M.R., Hoque, A.K.M., Begum, M., Kamal, M.M. and Uddin, M.I. (1993). Weed survey in wheat, lentil and mustard crops under Old Brahmaputra Floodplain and Young Brahmaputra and Jamuna Floodplain Agro-ecological zones. Bangladesh Agril. Univ. Res. Prog. 7, 160-172

Mapa, R.B., Somasiri, S. and Dassanayake, A.R. (2009). Soils of the Dry Zone of Sri Lanka. Morphology, Characterization and Classification. Soil Science Society of Sri Lanka. Special Publication No. 7, Sarvodaya Vishva Lekha ,Colombo, Sri Lanka.

Parida, B.C. (2002). Development and evaluation of star-cum cono-weeder for rice. Agric. Mechanization in Asia, Afr. Latin Am. 33(3), 21-22.

Rathnasekara, A.K.K.D., Weerasooriya, G.V.T.V., Ginigaddara, G.A.S. and Kahandage, P.D. (2013). Modification and evaluation of five row weeder for weed controlling in system of rice intensification. In Undergraduate Research Symposium 2013 Proceeding. Faculty of Agriculture, Sri Lanka: Rajarata University of Sri Lanka, p 86.

Remesan, R., Roopesh, M.S., Remya, N. and Preman, P.S. (2007). Wet land weeding - A comprehensive comparative study from South India. Agr Eng In: The CIGR E-Journal.9, 121. 
RNAM. (1983). Economic and Soil Commission for Asia and Pacific Regional Network for Agricultural Machinery. RNAM Test Codes and Procedures for Farm Machinery, Technical Series No. 12. Bangkok, Thailand: United Nations Industrial Development Organization.

Singh, G., Chaudhary, A.P. and Clough, D.S. (1988). Performance evaluation of mechanical reapers in Pakistan. AMA. 19, 47-52.

Singh, R.A. (1980). Soil physical analysis. New Delhi: Kalyani publishers.

Singh, T.P. and Bhosale, A.T. (2014). Comparative performance evaluation of different mechanical equipment for weed control in sugarcane crop in Northern-Western Tarai region of Uttarakhand. Afr. J. Agric. Res. 9(43), 3226 - 3232. DOI: 10.5897/AJAR2013.7289

Srinivas, I., Adake, R.V., Reddy, B.S., Korwar, G.R., Thyagaraj, C.R., Dange, A., Veeraprasad, G. and Raddy, C.R. (2010). Comparative performance of different power weeders in rain fed sweet sorghum crop. Indian J. Dryland Agric. Res. \& Dev. 25(2), 63-67.

Subudhi, C.R. (2004). Evaluation of weeding devices for upland rice in the Eastern Ghat of Orissa, India. Int. Rice Res. Notes 29(1), 79-80.

Tajuddin, A. (2006). Design, development and testing of engine operated weeder. Agr. Eng. Today. 30(5, 6), 25-29.

Tajuddin, A. (2009). Development of a power weeder for low land rice. IE (I). 90, 15-17.

Wijekoon, R.D.R., Bandara, M.H.M.A. and Weerasooriya, G.V.T.V. (2008). Design and development of low land power weeder. In Abstracts of Final Year Research, Faculty of Agriculture, Rajarata University of Sri Lanka, Vol. 03, p 45.

Yadav, R. and Pund, S. (2007a). Development and ergonomic evaluation of manual weeder. Agr. Eng. In: the CIGR E-journal. IX, 7 - 22.

Yadav, E.T. and Pund, A.K. (2007b). Characteristics of Indian weeders. Hyderabad, India: Wassan publication. 